\title{
Assessment of Quality of Life and Nurses' Knowledge among Hypertensive Elderly Patients at Sohag University Hospital.
}

\author{
* Shimaa Hassan Abd El-Fatah, * * Soad Sayed Bayomi * **Mohamed Ali El-Torky \\ * Geriatric Nursing Department, Faculty of Nursing, Sohag University \\ * * Assistant Professor of Community Health Nursing Faculty of Nursing, Assiut University \\ *** Professor of Community Medicine, Faculty of Medicine, Sohag University
}

\begin{abstract}
Hypertension has been a well-recognized condition in the elderly for a very long time and is prevalent in over $70 \%$ of the elderly population. It is estimated that the number of persons aged 65 years and older will increase to 72 million by the year 2030, which will in turn result in an increased rate of hypertension among the elderly. Aim: To assess the quality of life of elderly patients suffering from hypertension and nurses' knowledge regarding hypertension. Methods: A cross sectional descriptive research design was utilized in this study. This study was carried out at medical, dialysis, and neurological departments at Sohag University Hospital. Convenient sample consist of 178 elderly patients suffering from hypertension and 58 nurses. Data were collected at a period of six months starting from November 2011 to the end of April 2012, using two tools: First tool; is a structured interview sheet about Quality of life. Second tool: an interview questionnaire sheet to assess nurses' knowledge regarding hypertension. Results: $48.9 \%$ of patients had low QOL score, and there was a statistical significant difference between quality of life and sex \& level of education "P- value (.007\&.070)" respectively, and around one third of nurses $(32.7 \%)$ had poor level of knowledge about hypertension. There was a statistical significant difference between knowledge and age \& qualification of nurses "p- value (.052\&.090) respectively". Conclusion and Recommendations: Presence of gerontological nurses in outpatient clinics and hospital departments whom trained and have an active role in health promotion and disease prevention for that highly growing segment of population. People have to be educated through mass media on hypertension and its risk factors. People have to be educated on the importance of physical exercises and have to be encouraged to do them.
\end{abstract}

\section{Key Words: Hypertension, QOL, Knowledge, Patient, Nurses}

\section{Introduction:}

Aging is unique in each individual, and although the specific effects of that process cannot be predicted with accurateness, the majority of individuals will experience alterations in their sensory organs as they age. Old age is an unpreventable physiological state. It is thought that determining and solving the difficulties of elderly people might improve their quality of life (QOL) (Canbaz et al., 2003).

Life expectancy for the elderly in developed and developing countries has increased as a result of improvement in public health and medical advances, and the increase in the absolute and relative numbers of elderly people is one of the major features of the world demographic transition. Yang et al., (2011) reported that about sixty percent of the elderly people live in developing countries (Heydari et al., 2012). Change of Life expectancy at birth of Egyptian people from 69 years at 1990 to 75 years at 2009 for male 67 to 73 years, while for female 72 to 78 years (WHO, 2012).

Although high blood pressure should not be considered as a normal aspect of aging, there is clearly an age-associated increase in blood pressure and in the prevalence of hypertension. As one gets older, some difficulties arise in daily activities and QOL begins to weaken. QOL is also affected by health conditions, care and unattended requirements of elderly people (Arslantas et al., 2009).

Hypertension remains the first cause of cardiovascular risk and mortality worldwide, and, in people aged 65 or older, it has been duplicated in relation to four decades before. Also population aged 80 or older is increasing; the prevalence of hypertension in this group of people is above $60 \%$ and continues to grow. It is well known that hypertension is associated to other risk factors such as overweight, obesity (46.8\%), tobacco abuse, or hypercholesterolemia $(45.4 \%)$ (Extremera and Gomez, 2012).

Quality of life is a multidimensional concept comprised of several domains; physical/biological factors, symptom status, functional status, health perceptions, and overall well-being (Klimm et al., 2010). 
In general, quality of life can be influenced directly and indirectly by various disease related factors. Chronic diseases, such as cardiovascular diseases and mental disorders (e.g. depression) potentially decrease short-term and long term quality of life. Direct effects of the disease itself and side effects of the treatment may influence quality of life in patients with hypertension (Baune and Aljeesh, 2006).

Nursing care for hypertensive patients focuses on lowering and controlling the blood pressure without adverse effects and without undue cost. To achieve these goals, the nurse must support and teach the patient to adhere to the treatment regimen by implementing necessary lifestyle changes, taking medications as prescribed, and scheduling regular follow-up appointments with the health care provider to monitor progress or identify and treat any complications of disease or therapy (Cushman, 2001).

The gerontological nurse has a crucial and vital role in promoting the quality of life of elders, allowing the greatest potential for independence and self-direction in daily activities, enhancing their sense of control, and identifying the risk factors that might affect the quality of life either for elders and their families or caregivers (EL-Shazly and Mahmoud, 2007).

\section{Significant of the study:}

Hypertension is one of the most important causes of morbidity and mortality in the elderly. Hypertension has the greatest impact on global attributable mortality of any other risk factor and accounts for the third leading cause of global burden of disease. Hypertension and aging are major factors that contribute to cardiovascular morbidity and mortality, and both severely damage the heart (Smeltzer \& Bare, 2003 and da Silva et al., 2010).

\section{Aim of the study}

- Assess the quality of life of elderly patients suffering from hypertension

- Assesses nurses' knowledge regarding of hypertension.

\section{Methods:}

Research design:

A Descriptive, Cross Sectional research design was used in this study.

\section{Setting:}

This study was carried out at medical, dialysis, and neurological departments at Sohag University Hospital. The hospital provides free health care services for surrounding urban and rural areas.

\section{Subjects:-}

The subjects of the study consisted of:-

\section{1- Elderly patients:}

178 elderly patients were included selected from previous mention setting, according to following criteria

- Age: they should be 60 years and older.

- They should be able to communicate.

- They should agree to participate in the study.

- They are suffering from hypertension.

\section{2- Nurses: -}

All responded nurses (58) who are working in medical, dialysis and neurological departments at Sohag University Hospital during period of data collection.

Data were collected at a period of six months starting from starting November 2011 to end of April 2012.

\section{Tools of the study:}

Two tools were used for collecting data, these tools were tested by the researchers, and content of the tools was established by extensive literature review and pilot study. An Arabic questionnaire sheet was developed by the researchers, it includes two tools:-

I-First tool: to assess quality of life for patients includes two parts:-

Part (one):

Personal data: - it includes information about (name, age, Sex, marital status, occupation, level of education, and income).

Part (two): Quality of life assessment sheet:-

Quality of life (QOL) Scale regarding hypertension. The original Scale was constructed by Lehman (1986). This scale was modified by the investigator to measure the current concept under study. It consists of (50) items divided into six domains or subscales, the quality of life domains are physical health, psychological status, social relationships, selfdependence, family life, and spiritual/ religion/ personal beliefs.

1. The first subscale included (11) items covering physical health, which includes feeling fatigue, feeling lazy and keeping lying down most of the day, feeling of headache, blurred vision, taking enough amount of rest per day, recognize the surrounding environment, recognize the familiar faces, having minor accidents such as falling, Feeling restricted all the time, make any exercise, and share to carry out daily activities. 
2. The second subscale consists of (12) items reflecting the psychological status of patients which include feeling of pleasure of his/her life, feeling of good fun, laughs easily, able to express his/her feeling, feeling of self trust, feeling of helplessness, feeling of self burden on others, feeling of anxiety \& nervousness, feeling of suffocation, feeling of hopelessness about future, feeling of insecurity, and blames his/herself about something that occurred.

3. The third subscale included (9) items reflecting personal and social relationships which includes ability to build strong relationships, desire to be alone, difficulty in understanding people, difficulty of speech, find hard to concentrate, more forgetful, difficulty in learning new things, difficulty in solving problems, and carelessness of acts on others.

4. The fourth subscale included (9) items representing level of independence, which includes:

(a) Personal hygiene: Brushes teeth, bathes, and needs help with this care.

(b) Dress and Appearance: Wearing clothes independently, and wears clothes by assistance.

(c) Eating: Eats a large amount of food by his/her self and eats enough by assistance.

(d) Mobility: moving independently in the house, climbing stairs up and down independently, and moving independently out of the house.

5. The fifth subscale includes (4) items related to family life includes: laughing with family, feeling comfortable, security and privacy with family at home, and Feeling of worm \&rest at home.

6. The six subscale consists of (5) items used to collect data about spiritual concerns and personal beliefs, values and habits of religion which include taking care of prayer \& fasting, believing that work is religion, feeling that God is able to cure me, feeling satisfied when going to mosque or church, and having the feeling of guilt

II-Second tool: to assess nurses' knowledge about hypertension, it consists of two parts:-.

\section{Part (one):}

Socio demographic data: it includes information about age, marital status, qualifications and years of experience.

Part (two):

Nurses' knowledge about hypertension. The total number of questions were 20 .

Ethical considerations

- The purpose of this study was explained for every interviewed elderly patient and the nurses.

- Confidentiality of the information and oral consent from elderly patients and nurses for participation in the study were taken. The elderly patient and nurse have ethical right to agree or refuse participation in the study.

\section{Statistical analysis:}

The obtained data were reviewed, prepared for computer entry, coded, analyzed and tabulated. Descriptive statistics (frequencies\& percentage) as well as tests of significance (chi square test and ANOVA) were done using computer program SPSS version 16 . The probability of less them 0.05 was considered significant for all statistical tests.

- For the quality of life scale, scores ranging $(0,1$, and 2) were respectively given to the responses of (never, sometimes, and always). The scoring was reversed for negative items. The scores of the items were summed up and the total was divided by the number of the items, given a mean score for quality of life. These scores converted into percent score. Scoring system used in QOL scale had three levels (low, moderate, and high). The total score was 100 point, who obtained less than 50 points considered low QOL, who obtained $50 \leq 75$ points considered moderate QOL, and who scored more than 75 points considered high QOL.

- For assessment nurses' knowledge scale, a correct response was scored 1 grade and incorrect zero. The score of each item summed-up and then converted into percent score $($ Poor $=$ score $<50 \%$, satisfied $=$ score $50-65 \%$, and good $=$ score $>65 \%)($ El-Houfey, 2007). 


\section{$\underline{\text { Results: }}$}

Table (1): Socio-demographic characteristics of studied elderly patients.

\begin{tabular}{|c|c|c|}
\hline Characteristic & $\mathbf{N}(\mathbf{1 7 8})$ & $(\%)$ \\
\hline \multicolumn{3}{|l|}{ Age: } \\
\hline $60-69$ & 130 & 73.0 \\
\hline $70-79$ & 37 & 20.8 \\
\hline$\geq 80$ & 11 & 6.2 \\
\hline \multicolumn{3}{|l|}{ Sex } \\
\hline Male & 85 & 47.8 \\
\hline Female & 93 & 52.2 \\
\hline \multicolumn{3}{|l|}{ Residence: } \\
\hline Urban & 55 & 30.9 \\
\hline Rural & 123 & 69.1 \\
\hline \multicolumn{3}{|l|}{ Level of education: } \\
\hline Illiterate & 116 & 65.1 \\
\hline Read \& write & 28 & 15.7 \\
\hline Primary & 8 & 4.5 \\
\hline Preparatory & 9 & 5.1 \\
\hline Secondary & 8 & 4.5 \\
\hline University & 9 & 5.1 \\
\hline \multicolumn{3}{|l|}{ Marital status: } \\
\hline Single & 2 & 1.1 \\
\hline Married & 117 & 65.7 \\
\hline Widow & 51 & 28.7 \\
\hline Divorced & 8 & 4.5 \\
\hline \multicolumn{3}{|l|}{ Occupation: } \\
\hline Farmer & 34 & 19.2 \\
\hline Housewife & 83 & 46.6 \\
\hline Retired & 15 & 8.4 \\
\hline Employee & 20 & 11.2 \\
\hline Not work & 26 & 14.6 \\
\hline \multicolumn{3}{|l|}{ Income: } \\
\hline$<100$ & 55 & 30.9 \\
\hline
\end{tabular}

Table (2): Stage and duration of hypertension among patients.

\begin{tabular}{|l|c|c|}
\hline \multicolumn{1}{|c|}{ Items } & $\begin{array}{c}\text { No. }(\mathbf{n}= \\
\text { 178) }\end{array}$ & \% \\
\hline $\begin{array}{l}\text { Classification of } \\
\text { hypertension: } \\
\text { Controlled } \\
<140 / 90 \mathrm{mmhg}\end{array}$ & 28 & 15.7 \\
\hline $\begin{array}{l}\text { Stage one } \geq 140- \\
\text { 159/90-99 }\end{array}$ & 58 & 32.6 \\
\hline $\begin{array}{l}\text { Stage two 160- } \\
\text { 180/100-109 }\end{array}$ & 55 & 30.9 \\
\hline $\begin{array}{l}\text { Stage three }>180 / 110 \\
\text { Duration of } \\
\text { hypertension: } \\
<1 \text { year }\end{array}$ & 37 & 20.8 \\
\hline 1- 5 years & 11 & 6.2 \\
\hline 6- 10 years & 39 & 21.9 \\
\hline$>10$ years & & \\
\hline
\end{tabular}


Table (3): Distribution of elderly patients regarding their total quality of life domains score.

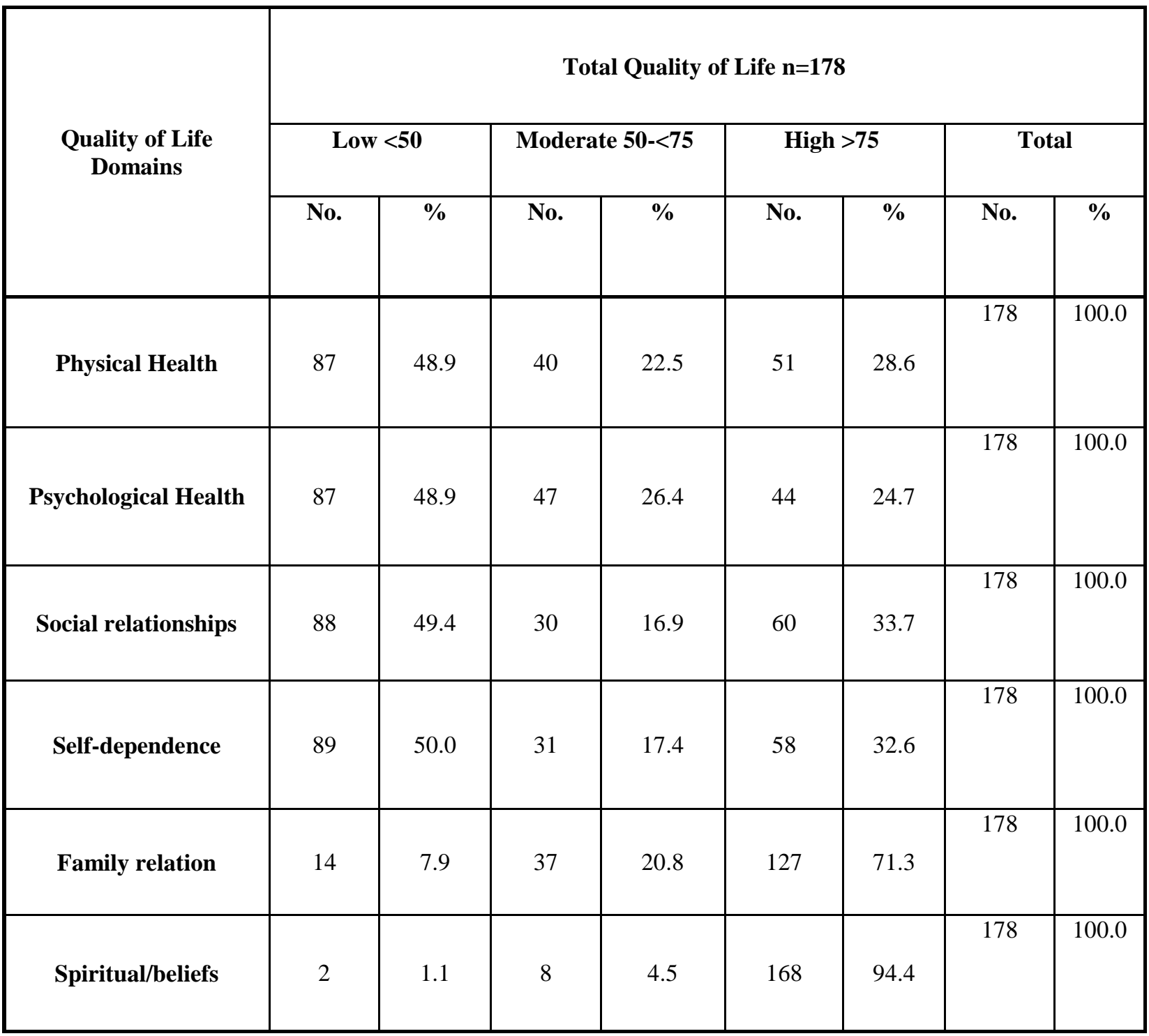


Table (4): Relation between total quality of life and sociodemographic characteristics of elderly patients.

\begin{tabular}{|c|c|c|c|c|c|c|c|c|}
\hline \multirow{3}{*}{ Personal Data } & \multicolumn{6}{|c|}{ Total QOL $n=178$} & \multirow{3}{*}{ X2 test } & \multirow{3}{*}{ P-Valuc } \\
\hline & \multicolumn{2}{|c|}{ Low } & \multicolumn{2}{|c|}{ Moderate } & \multicolumn{2}{|c|}{ High } & & \\
\hline & No. & $\%$ & No. & $\%$ & No. & $\%$ & & \\
\hline $\begin{array}{l}\text { Age: } \\
60-69\end{array}$ & 56 & 43.0 & 34 & 26.2 & 40 & 30.8 & \multirow{3}{*}{13.61} & \multirow{3}{*}{.191} \\
\hline $70-79$ & 24 & 64.9 & 8 & 21.6 & 5 & 13.5 & & \\
\hline$\geq 80$ & 7 & 63.6 & 4 & 36.4 & 0 & 0.0 & & \\
\hline $\begin{array}{l}\text { Sex: } \\
\text { Male }\end{array}$ & 33 & 38.8 & 22 & 25.9 & 30 & 35.3 & \multirow[t]{2}{*}{9.816} & \multirow[t]{2}{*}{$.007^{*}$} \\
\hline Female & 54 & 58.1 & 24 & 25.8 & 15 & 16.1 & & \\
\hline $\begin{array}{l}\text { Residence: } \\
\text { Urban }\end{array}$ & 30 & 54.5 & 14 & 25.5 & 11 & 20.0 & \multirow{2}{*}{1.406} & \multirow{2}{*}{.495} \\
\hline Rural & 57 & 46.3 & 32 & 26.0 & 34 & 27.6 & & \\
\hline $\begin{array}{l}\text { Level of education: } \\
\text { Illiterate }\end{array}$ & 65 & 56.0 & 30 & 25.9 & 21 & 18.1 & \multirow{6}{*}{36.77} & \multirow{6}{*}{$.000^{*}$} \\
\hline Read \& write & 13 & 46.4 & 8 & 28.6 & 7 & 25.0 & & \\
\hline Primary & 3 & 37.5 & 1 & 12.5 & 4 & 50.0 & & \\
\hline Preparatory & 4 & 44.4 & 4 & 44.4 & 1 & 11.1 & & \\
\hline Secondary & 2 & 25.0 & 3 & 37.5 & 3 & 37.5 & & \\
\hline University & 0 & 0.0 & 0 & 0.0 & 9 & 100 & & \\
\hline $\begin{array}{l}\text { Marital status: } \\
\text { Single }\end{array}$ & 0 & 0.0 & 1 & 50.0 & 1 & 50.0 & \multirow{4}{*}{4.897} & \multirow{4}{*}{.557} \\
\hline Married & 55 & 47.0 & 29 & 24.8 & 33 & 28.2 & & \\
\hline Widow & 27 & 52.9 & 15 & 29.4 & 9 & 17.6 & & \\
\hline Divorced & 5 & 62.5 & 1 & 12.5 & 2 & 25.0 & & \\
\hline $\begin{array}{l}\text { Occupation: } \\
\text { Farmer }\end{array}$ & 17 & 50.0 & 9 & 26.5 & 8 & 23.5 & \multirow{5}{*}{14.467} & \multirow{5}{*}{.070} \\
\hline Housewife & 46 & 55.4 & 24 & 28.9 & 13 & 15.7 & & \\
\hline Retired & 3 & 20.0 & 4 & 26.7 & 8 & 53.3 & & \\
\hline Employee & 9 & 45.0 & 3 & 15.0 & 8 & 40.0 & & \\
\hline Not work & 12 & 46.2 & 6 & 23.1 & 8 & 30.8 & & \\
\hline $\begin{array}{l}\text { Income: } \\
<100\end{array}$ & 30 & 54.5 & 17 & 30.9 & 8 & 14.5 & \multirow{5}{*}{10.510} & \multirow{5}{*}{.231} \\
\hline $100-399$ & 15 & 55.6 & 4 & 14.8 & 8 & 29.6 & & \\
\hline $400-799$ & 18 & 50.0 & 9 & 25.0 & 9 & 25.0 & & \\
\hline $800-1199$ & 22 & 43.1 & 14 & 27.5 & 15 & 29.4 & & \\
\hline$\geq 1200$ & 2 & 22.2 & 2 & 22.2 & 5 & 55.6 & & \\
\hline
\end{tabular}

${ }^{*}$ There is significant difference - Significant at $\mathbf{P}<0.05$ 
Table (5): ANOVAs test among each domain for quality of life among elderly patients.

\begin{tabular}{|c|c|c|c|c|}
\hline Items & Grades of QOL & $\begin{array}{c}\text { means } \pm \text { Std. } \\
\text { Deviation }\end{array}$ & F-test & $P$ - value \\
\hline \multirow{3}{*}{ Physical } & Low & $8.3448 \pm 3.156$ & \multirow{3}{*}{25.665} & \multirow{3}{*}{$0.000 *$} \\
\hline & Moderate & $9.578 \pm 3.152$ & & \\
\hline & high & $12.644 \pm 3.600$ & & \\
\hline \multirow{3}{*}{ Psychological } & Low & $8.333 \pm 4.502$ & \multirow{3}{*}{134.541} & \multirow{3}{*}{$0.000 *$} \\
\hline & Moderate & $15.326 \pm 3.232$ & & \\
\hline & high & $19.511 \pm 3.094$ & & \\
\hline \multirow{3}{*}{ Social } & Low & $8.379 \pm 3.383$ & \multirow{3}{*}{69.054} & \multirow{3}{*}{0.000} \\
\hline & Moderate & $10.870 \pm 2.535$ & & \\
\hline & high & $15.000 \pm 2.923$ & & \\
\hline \multirow{3}{*}{ Self dependence } & Low & $10.885 \pm 4.659$ & \multirow{3}{*}{47.066} & \multirow{3}{*}{$0.000^{*}$} \\
\hline & Moderate & $15.044 \pm 3.238$ & & \\
\hline & high & $17.200 \pm 1.618$ & & \\
\hline \multirow{3}{*}{ Family life } & Low & $5.241 \pm 2.367$ & \multirow{3}{*}{28.430} & \multirow{3}{*}{$0.000 *$} \\
\hline & Moderate & $7.239 \pm 1.448$ & & \\
\hline & high & $7.511 \pm 1.079$ & & \\
\hline \multirow{3}{*}{ Spiritual } & Low & $8.920 \pm 1.912$ & \multirow{3}{*}{9.444} & \multirow{3}{*}{$0.000 *$} \\
\hline & Moderate & $9.804 \pm .58193$ & & \\
\hline & high & $9.8444 \pm .42403$ & & \\
\hline
\end{tabular}

${ }^{*}$ There is significant difference - Significant at $\mathrm{P}<0.05$ 
Table (6): Socio demographic characteristics of the studied nurses.

\begin{tabular}{|c|c|c|}
\hline Items & No $=58$ & $\%$ \\
\hline $\begin{array}{l}\text { Age: } \\
<20 \text { years }\end{array}$ & 9 & 15.5 \\
\hline 20-30 years & 43 & 74.2 \\
\hline$>30$ years & 6 & 10.3 \\
\hline $\begin{array}{l}\text { Marital Status: } \\
\text { Single }\end{array}$ & 24 & 41.4 \\
\hline Married & 33 & 56.9 \\
\hline Divorce & 1 & 1.7 \\
\hline $\begin{array}{l}\text { Qualifications: } \\
\text { Diploma of nursing } 3 \text { years }\end{array}$ & 50 & 86.2 \\
\hline Institute of nursing & 8 & 13.8 \\
\hline $\begin{array}{l}\text { Years of experience: } \\
<1 \text { year }\end{array}$ & 5 & 8.6 \\
\hline $1-4$ years & 20 & 34.5 \\
\hline 5-9 years & 23 & 39.7 \\
\hline$\geq 10$ years & 10 & 17.2 \\
\hline $\begin{array}{l}\text { Previously of attended training programs about hypertension: } \\
\text { Yes }\end{array}$ & 6 & 10.3 \\
\hline No & 52 & 89.7 \\
\hline $\begin{array}{l}\text { Period which taken training? } \\
<1 \text { year }\end{array}$ & 6 & 100.0 \\
\hline $\begin{array}{l}\text { Trainer: } \\
\text { Doctors }\end{array}$ & 4 & 66.7 \\
\hline Head nurse & 2 & 33.3 \\
\hline $\begin{array}{l}\text { Regularity of training: } \\
\text { Yes }\end{array}$ & 3 & 50.0 \\
\hline No & 3 & 50.0 \\
\hline
\end{tabular}




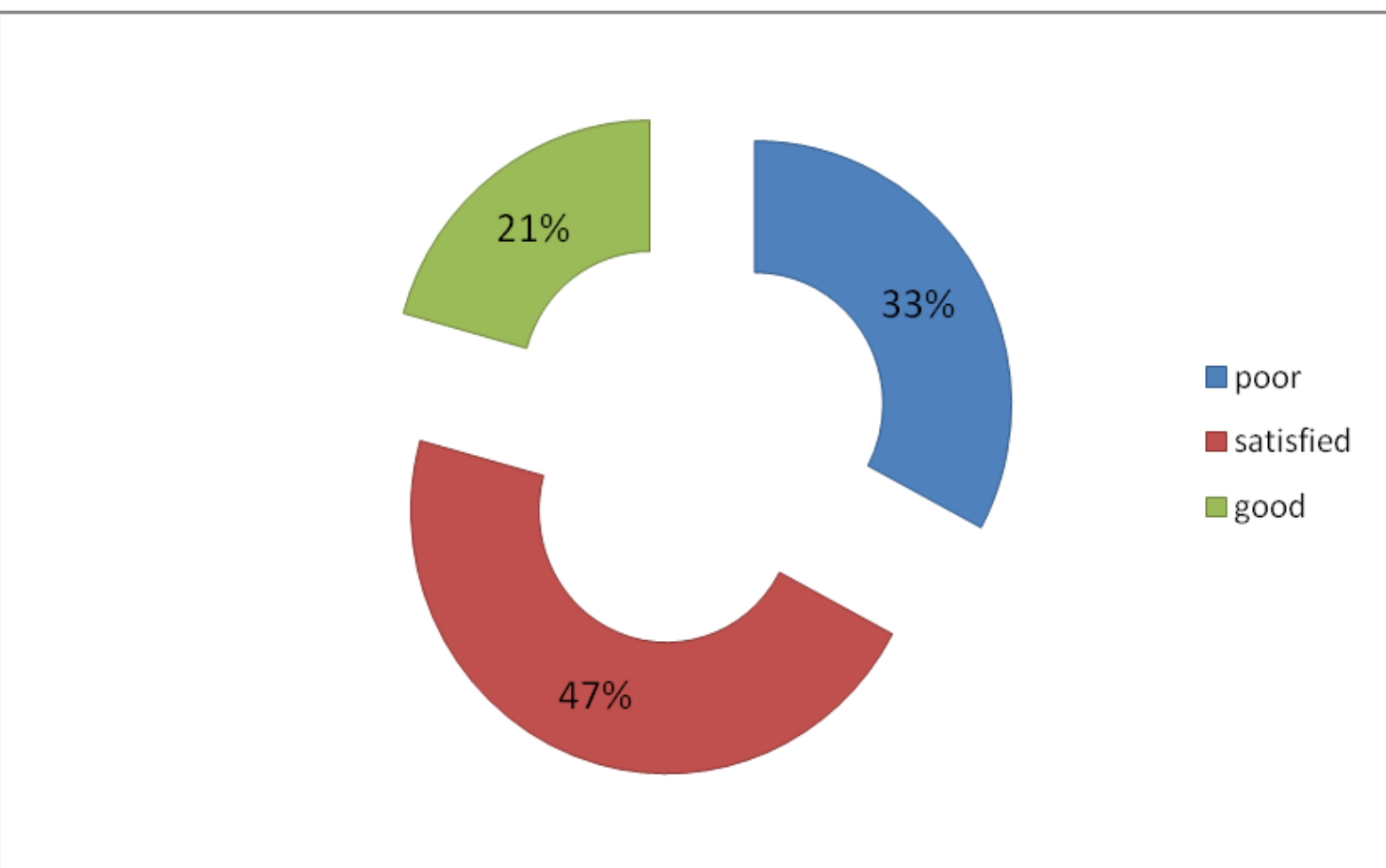

Figure (1): Total knowledge scores obtained by nurses

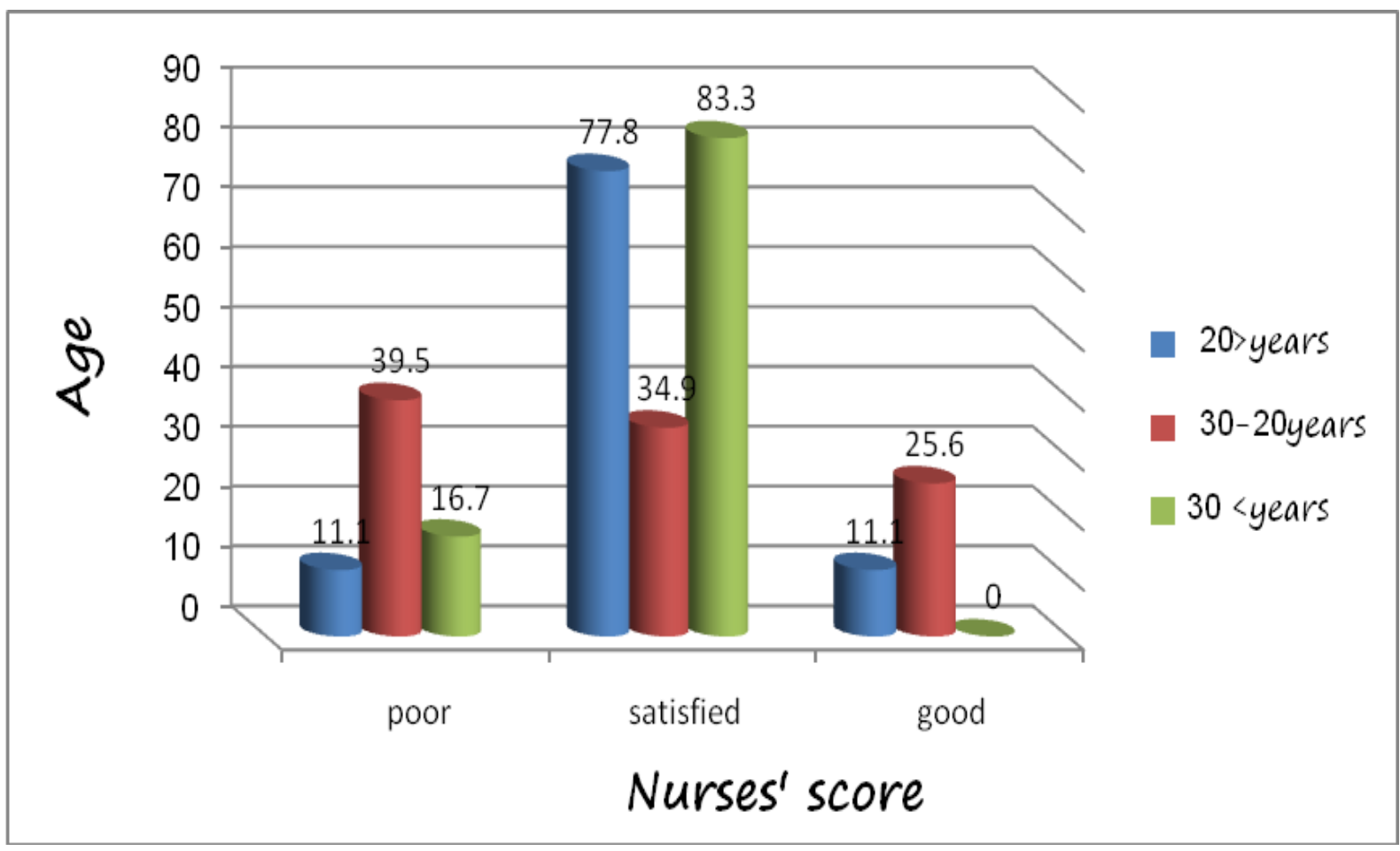

Figure (2): Relation between nurses' score and age 


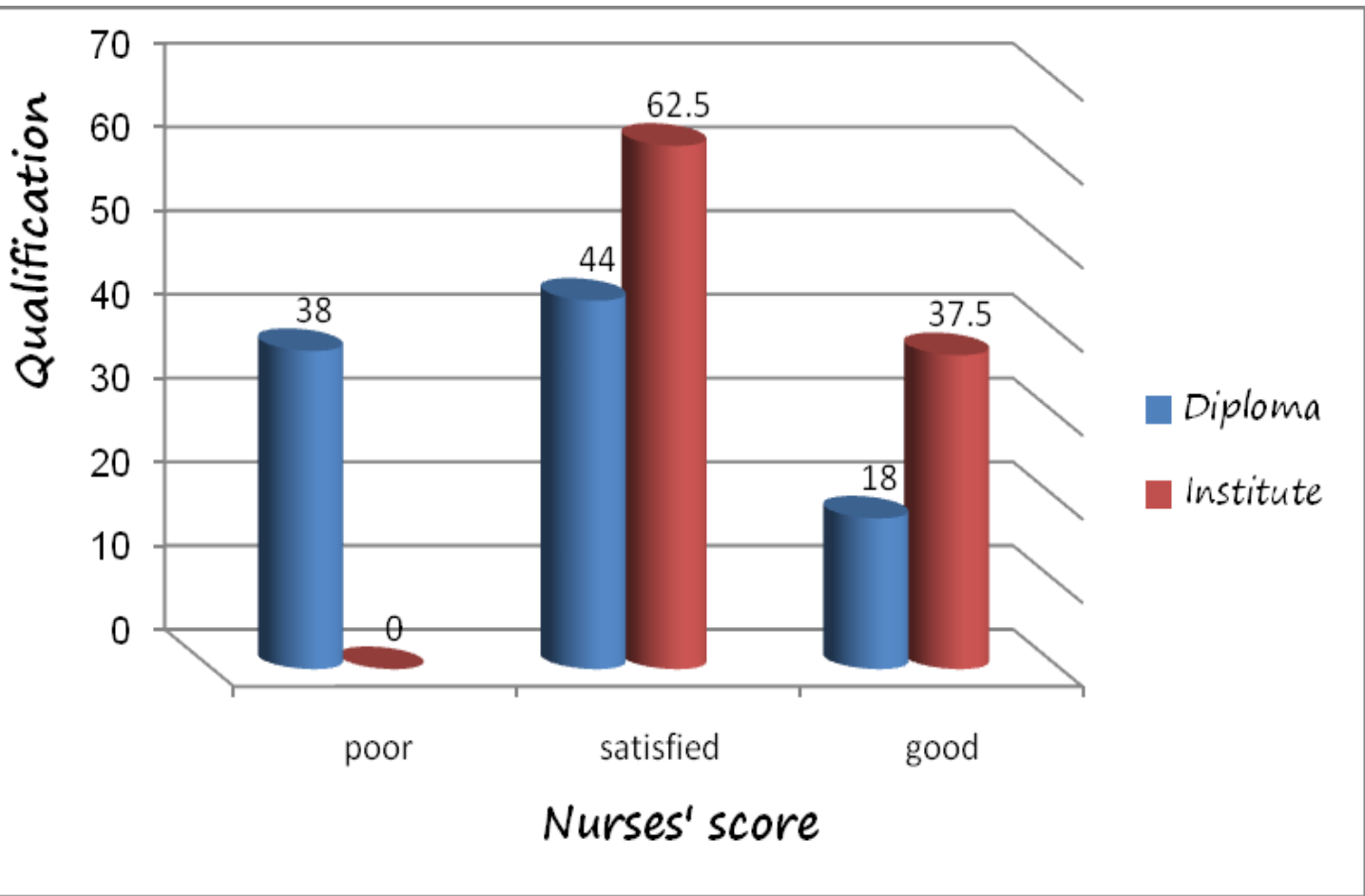

Figure (3): Relation between nurses' score and qualification

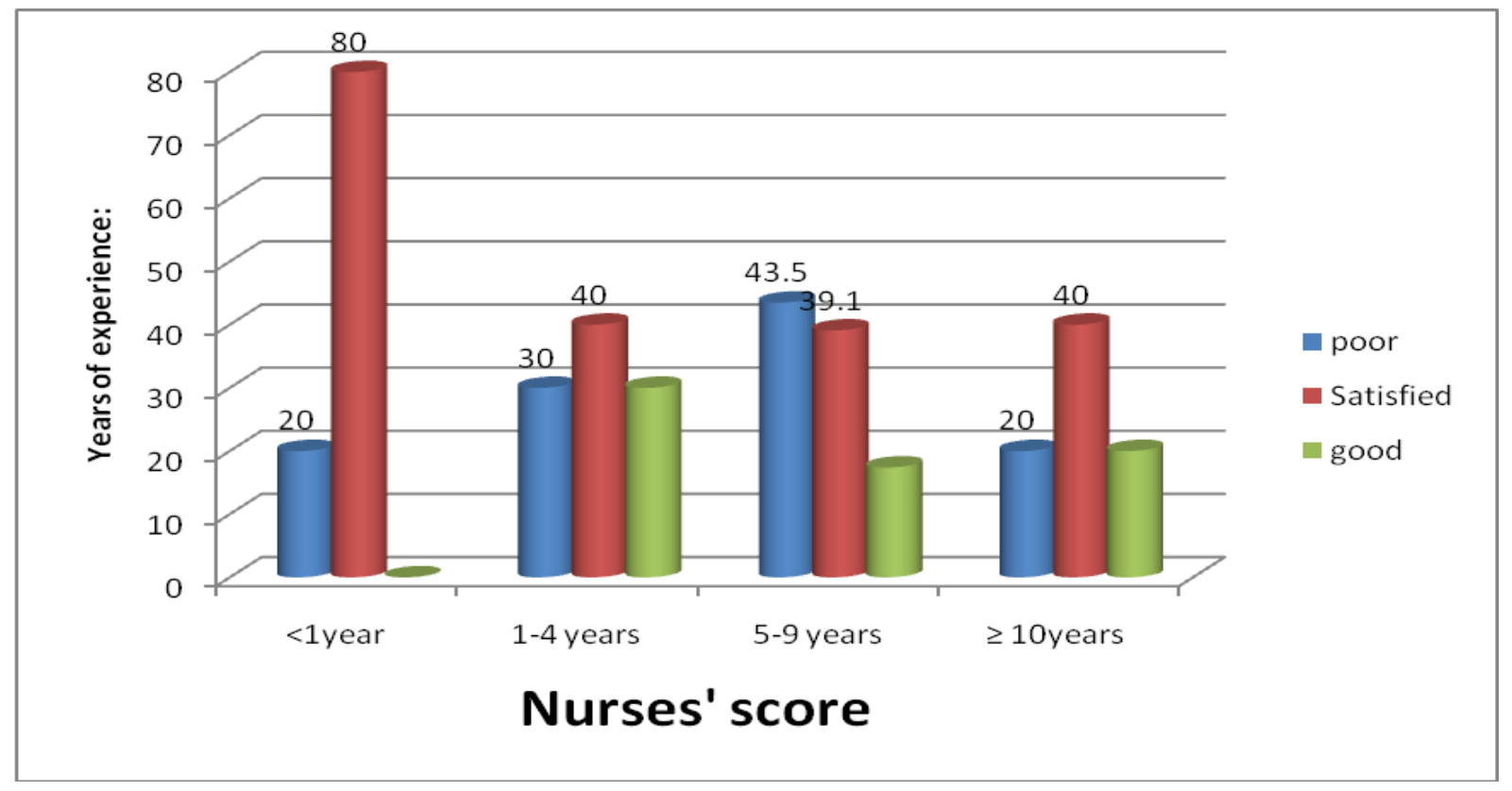

Figure (4): Relation between nurses' score and years of experience 
Table (1): Shows the distribution of elderly patients according to their sociodemographic characteristics at Sohag University Hospital; Regarding their age, it was noticed that, nearly three quarters $(73 \%)$ of the patients aged between 60 -69 years, while their sex, it was found that little only more than half $(52.2 \%)$ of them were females. Regarding to their residence, it was found that more than two thirds of them (69.1\%) lived in rural areas. It was observed that about two thirds of the elderly patients $(65.1 \%)$ were illiterate, about two thirds of them $(65.7 \%)$ were married, less than half of the elderly patients $(46.6 \%)$ were housewives. Concerning income, nearly one third of them $(30.9 \%)$ had fewer than 100 pounds.

Table (2): Shows the distribution of elderly patients according to stage and duration of hypertension; it was revealed that nearly third of the patients $(32.6 \%)$ hade stage one of hypertension, while $20.8 \%$ hade stage three of hypertension. Regarding duration of hypertension, less than half of them $47.8 \%$ had hypertension ranged from 1-5 years, while $6.2 \%$ had hypertension for 10years and more.

Table (3): Shows the distribution of elderly patients regarding their total quality of life domains score at Sohag University Hospital. Regarding the physical QOL domain, nearly half of the patients (48.9\%) had low score; while $24.7 \%$ of them had high score for psychological QOL domain. Concerning the social \& self-dependence QOL domains, (49.9\%, and 50.0\%) of the patients had low score respectively. As regards the Family life QOL domain, nearly three quarters $(71.3 \%)$ of the patients had high score, while spiritual/beliefs QOL domain, majority of the patients $(94.4 \%)$ had high score. As regards the total scores of QOL domains, around half of the patients (48.9\%) had low QOL score, while $25.3 \%$ of them had high QOL score.

Table (4): Shows the relation between total quality of life and sociodemographic characteristics of elderly patients at Sohag University Hospital. There was a statistical significant difference between quality of life and sex \& level of education of patients at Pvalue (.007\&.070) respectively, while no a statistical significant difference between total QOL and age, residence, marital status, occupation, and income of patients.

Table (5): shows ANOVAs test among each domains for quality of life among elderly patients at Sohag university hospital. That there is a statistical significant difference among three classifications for domains of quality of life and total QOL.

Table (6): Illustrates the distribution of socio demographic characteristics of the studied nurses at Sohag University Hospital. Nearly three quarters of the nurses (74.2\%) had age ranged from 20-30 years; More than half of the nurses $(56.9 \%)$ were married. A high percentage of the nurses $(86.2 \%)$ had diploma of nursing 3 years, nearly two fifths of the nurses $(39.7 \%)$ ranged from 5 to more than 9 years of experience, As regards previously attended training programs, it was found that the majority of them $(89.7 \%)$ were not attending training program about hypertension.

\section{Discussion:}

Hypertension is one of the main risk factors for cardiovascular diseases. Health teams should pay special attention to the control problem, which in turn is closely related to the treatment adherence process. Particularly physicians, nurses, nursing technicians and auxiliaries should be properly advised about the particularities of the disease and treatments to achieve better control of the disease. Nursing carries a large responsibility in care delivery to hypertensive individuals (da Silva et al., 2010).

As regards socio-demographic characteristics of the studied elderly patients, the findings of the present study showed that $(73.0 \%)$ of them had age ranged between 60-69 years, this is supported by Naing et al., (2010), who found that more than half of the elderly patients admitted to hospital for hypertension were 60-69 years. This finding disagrees with Prior et al., (2012) who found that $(39.2 \%)$ of the studied patients had age between 60-69 years.

Regards their sex, $(52.2 \%)$ of them were females and the rest of them $(47.8 \%)$ were males. This finding is nearly similar to the result of Chacón et al., (2008) who found in his study that females admitted to hospital constituted (53\%) and the males constituted $(47 \%)$. This result also supported by Lima et al., (2009) who found in his study that the hypertension in females was slightly more than in the elderly males.

As the results indicate the majority of the studied sample was female and they have longer life expectancy than males. According to report of American Heart Association, (2012) a higher percentage of men than women have hypertension until age 45. From ages 45-54 and 55-64, the percentage of men and women is similar; after that a much higher percentage of women than men have hypertension.

The present study disagree with Mostafa, (2007) who studied hypertensive patients in outpatient clinic at Sohag University Hospital and reported that females were less likely than males to have hypertension. 
Concerning the place of residence, results revealed that more than two thirds $(69.1 \%)$ of them were living in the rural areas and the rest (30.9\%) of them were living in urban areas. This finding is nearly similar to the results of Mostafa, (2007) who stated that about three quarters of their studied sample lived in rural areas. On the other hand, the present study disagree with Arslantas et al., (2008) who reported that the prevalence of hypertension is higher in urban than rural areas.

Concerning their educational level, it was observed that illiteracy have the highest percentage $(65.1 \%)$ in our studied sample, While $(15.7 \%)$ of them can read and write. The current results are similar to Mostafa, (2007) who reported that the majority of the studied sample were illiterate. On the other hand, the present study disagree with Mahmoud, (2007) who studied the prevalence of hypertension among people more than 35 years old in Sohag city and reported that more than half of the studied sample ( $50.9 \%$ ) were educated. This can be interpreted as the difference between the studies might be due to the differences in study populations.

Concerning their marital status, about two thirds $(65.7 \%)$ of them were married. This finding is nearly similar to the results of Jesus et al., (2008) who found in his study that $(66.9 \%)$ of the studied sample were married.

As regards their occupation, $(46.6 \%)$ of them were housewives. This finding is nearly similar to the results of Chacón et al., (2008) who found in his study that $(47.8 \%)$ of the studied sample were housewives.

According to the socio- economic level, it was noticed that the majority of the studied patients were with low socio- economic level. This agrees with Baune and Aljeesh, (2006) who found that the majority of the studied sample were with low socioeconomic level. Also, supported with the report of World Health Organization, (2012) which reported that the prevalence of hypertension is highest in some low-income countries in Africa, whereas public health interventions have reduced its prevalence in many high-income countries.

As regards classification of hypertension, it was found that nearly one third $(32.6 \%)$ of them had stage one of hypertension (140-159/90-99 mmg). This finding is consistent with the study conducted in Minichal-Brazil by Melchiors et al., (2010) who found that $(31.4 \%)$ of the studied sample had stage one of hypertension.

Concerning duration of hypertension, (47.8\%) of them had diagnosis of hypertension between 1-5years, while $(23.6 \%, 21.9 \%$, and $6.2 \%)$ of them had < 1 year, 6-10years, and >10years respectively. This finding is nearly similar to the results of Melchiors et al., (2010) who reported in his study that $(41.5 \%)$ of them had diagnosis of hypertension between 1-5years.

The present study illustrates that there is no statistical difference between quality of life of the studied patients and their age. This is consistent with Baune and Aljeesh, (2006) who found no significant difference between quality of life of the studied patients and their age, while this study disagrees with Chia et al., (2003) \& Fahmy (2010) who reported that QOL scores declined with age. Difference between the studies might be due to the differences in study populations. This difference is supported with multi-studies which found no association between age and HRQOL of participants. It is probably that we investigated the HQOL of elderly on a base of questionnaire, and we did not measure other important dimensions of HQOL, such as health status of participants according to clinical and Para clinical findings whereas elderly people experience diseases and impairments that threaten their quality of life (Luleci et al., 2008).

The current study illustrate that there is a significant difference between quality of life of the studied patient and their sex. QOL scores declined with female. This finding is consistent with Tajvar et al., (2008) who reported that QOL scores declined with female.

Moreover, the present study is in the same line with Chia et al., (2003) who found that women had slightly poorer quality of life than men. This may be related to the fact that women are high risk for hypertension after menopause than men and this lead to decrease QOL.

The current results can be interpreted as significant gender inequalities in health in Egypt. In general, Egyptian women (particularly old women) have less access to information, education, and employment and in overall of disadvantaged economic status and social position compared with men. Similarly studies of HRQOL worldwide including Finland, Taiwan, Poland and Croatia, Japan and Korea have found that women were less advantaged group compared to male group. Although women on average live longer than men, they report more illness than men.

The current study illustrates that there are no statistically significant difference between quality of life of the studied patients and their residences. This disagrees with Fahmy, (2010) who found that there are statistically significant difference between quality of life of the studied patients and their residences.

The current study illustrates that there are statistically significant difference between quality of life of the studied patients and their level of 
education. The present study shows that QOL scores increased with education. This finding is in the same line with Nutheti et al., (2006) \& Heydar et al., (2012) who found that QOL scores increased with education. This may be explained by the educated elderly use health services more than the illiterate one and this is important in early treatment of any impairment and lead to improve QOL.

In accordance to earlier studies Guler and Akal, (2009), the present study showed a relationship between education as a significant positive contributor and overall QOL. According to Lasheras et al., (2001) stated that lower educational level is associated with unhappiness, poor social relationships, poor self-assessed health, and sensory problems among the elderly. Education is an important indicator that may directly or indirectly influence QOL through its association with higher social class and economic status.

On the other hand, Baune and Aljeesh, (2006) found education had no significant impact on any of the QOL domains among patients with hypertension.

The current study illustrates that there is no a statistical difference between quality of life of the studied patients and their marital status. This finding is consistent with Tajvar et al., (2008) who found that marital status was not associated with the quality of life of elderly people. It is in contrast with Lee et al., (2005) who stated that married participants had a higher average score of QOL than the singles, divorced, widows and widowers. This difference can be interpreted due to difference in setting of study and value and tradition of every country.

The present study illustrates that there is no statistical difference between quality of life of the studied patients and their income. This study disagrees with Baune and Aljeesh, (2006) who found that there is a statistically significant difference between QOL and income.

As Regards socio-demographic characteristics of the studied nurses presented in table (13), the findings of the present study showed that the majority of the nurses' ages ranged between 20-30 years, less than three fifths of them were married, and around two fifths of them had 5 to 9 years of experience. Highest percentage of them had diploma of nursing.

These findings are in the same line with Hassan, (2011) and El-arab et al., (2012) who found that the majority of the nurses ages ranged from 20-30 years, married, and had diploma of nursing. The majority of their experiences range from 5 to more than 10 years.

On the other hand, these findings are in contrast with Millman, (2011) who stated that (6.2\%) only of the studied nurses had age ranged from 20-30 years, $(6.1 \%)$ only of them had diploma. Also, the current study disagrees with da Silva et al., (2010) who stated that about half of the studied nurses were up to 40 years old $(50.9 \%)$.

As regards previously attended training programs, it was found that $(89.7 \%)$ of the studied nurses did not attend training program about hypertension. This finding was in agreement with Mersal and Keshk, (2012) who stated that approximately three quarters $(75.9 \%)$ of nurses did not attend training program about health education.

This result is in contrast with da Silva et al., (2010) stated in his study that $(41.9 \%)$ of studied nurses mentioned they had never participated in courses about arterial hypertension. Also, this study disagrees with Tweed and Tweed, (2008) who stated in their study that $(83 \%)$ of the studied nurses attended an educational program.

The results reveal also that the general level of nurses' knowledge on hypertension is relatively fair at Sohag University Hospital. Insufficient knowledge is not being translated into practice. These results are in same line with Mohammed, (2010) who found that nurse' knowledge and compliance with universal precautions was generally poor. These results may be attributed to the fact that they are not concerned with reading updated information.

On the other hand, nurses' knowledge scores about hypertension show that about one fifth of the studied nurses had good knowledge. This finding disagrees with Isioma, (2012) who studied the Nurses knowledge and attitude in the prevention and management of hypertension in primary health care centers in Delta state Nigeria and reported that $(72 \%)$ of nurses had good knowledge about hypertension.

The current study illustrate that there is a statistically significant difference between nurses' knowledge score and their age. This finding is supported with Viera et al., (2008) who found in their study that there is significant difference between knowledge and age.

On the other hand, the present results disagree with Vloet et al., (2002) \&Tweed and Tweed, (2008) who found that there is no statistically significant difference between knowledge and age of nurses. Also, disagree with Adika et al., (2012) who reported that there is no statistically significant 
difference between nurses' knowledge scores with age.

For marital status, there is no statistically significant relationship between nurses' knowledge and their marital status. This finding disagrees with Adika et al., (2012) who studied Knowledge and behavior of nurses towards care of elderly stroke patients in Nigeria and found that there is statistically significant relationship between nurses' knowledge and their marital status.

The current study illustrates that there is statistically significant difference between nurses' knowledge score and their qualification. It also reveals that the total score of nurse's knowledge having Technical institute of nursing had significantly higher scores than those who have Secondary nursing diploma. This finding agrees with Ali, (2010) who stated that the total score of nurse's knowledge having Technical institute of nursing had significantly higher scores than nurses who have Secondary nursing diploma. On the other hand, this finding disagrees with Viera et al., (2008) and Elarab et al., (2012) who found in their study that there was no statistically significant difference between knowledge of studied sample and their qualification.

The current study illustrates that there is no statistically significant difference between nurses' knowledge score and their duration of experience. This finding disagrees with Hassan, (2011) who found a statistically significant difference between nurse's knowledge scores and their duration of experience.

In the present study total scores of nurses knowledge having work experience less than one year were higher than those who have work experience ranged from, $1<5$ years, from $5<10$ and more than 10 years. This result is supported by Ali, (2010) who found work experience less than one year were higher than those who have work experience ranged from, $1<5$ years, from $5<10$, from $10<15$ and more 15 years. Also, supported by Gamal, (2005) \& Hassan and Aboulazm, (2007) who found that the highest mean score of knowledge was among youngest nurses, those who have least of experience. On the other hand, this finding disagrees with the results of the study conducted by chudleigha et al., (2005) who found that nurses knowledge scores related to infection control measures in neonatal intensive care units were significantly better for more senior nurses than junior nurses.

The current study illustrates that there is no statistically significant difference between nurses' knowledge score and training program about hypertension. This finding disagrees with Zaky, (2009) who found that total score of nurses' knowledge who attended training course was higher than those who didn't attend training course. This difference may be interpreted by the small number of nurses who attended the training program about hypertension.

\section{Conclusions:}

Based on the results of the present study it can be concluded that:

- Hypertensive elderly patients have poor QOL particularly elderly women and those with lower education.

- Nurses' knowledge regarding hypertension in medical, dialysis, and neurological departments at Sohag University Hospital are inadequate.

\section{References:}

1. Adika V., Akwagbe R., Joffa A., Apiyanteide F., and Zuokemefa B., (2012): Knowledge and behavior of nurses towards care of elderly stroke patients in Bayelsa state - Nigeria, International Journal of Tropical Medicine, Vol 7, No 2, P 7479.

2. Ali M., (2010):Assessment of Nurse's Knowledge and Performance Related to Universal Infection Control Precautions (UICP) at Mallawy general hospital departments, Assiut University, Faculty of Nursing, Adult Nursing Department, P 44-68.

3. American Heart Association., (2012): Heart Disease and Stroke Statistics-2012 Update. Available http://www.americanheart.org/presenter.jhtm.

4. Arslantas D., Ünsala A., Metintasa S., Koca F. and Arslantas A., (2009): Life quality and daily life activities of elderly people in rural areas, Eskişehir (Turkey), Archives of Gerontology and Geriatrics, Volume 48, Issue 2, March-April 2009, P 127-131.

5. Baune B., and Aljeesh Y., (2006): Annals of General Psychiatry, The association of psychological stress and health related quality of life among patients with stroke and hypertension in Gaza Strip, Annals of General Psychiatry 2006, Vol 5, P 6.

6. Canbaz S., Sunter T., Dabak S., and Peksen Y., (2003): The Prevalence of Chronic Diseases and Quality of Life in Elderly People in Samsun, Turk Journal of Medical science, Vol 33, No 10, P 335-340.

7. Chacón E., Ulloa C., and Bixby L., (2008): Factors associated with hypertension prevalence, 
Unawareness and treatment among Costa Rican elderly, Public Health, Vol 8, P 275.

8. Chia E., Mitchell P., Rochtchina E., Foran S., and Wan J., (2003): Unilateral visual impairment and health related quality of life: the Blue Mountains Eye Study British Journal of Ophthalmology, Vol 87, No 4, P 392-395.

9. Chudleigha J., Fletcherb M., and Goulde D., (2005): Infection control in neonatal intensive care units in department of children's nursing, university of the West of England, department of applied biologgcal sciences pubmed. J Hosp infect. J.chudleigh @City.ac.UK.

10. Cushman W., (2001): Current Hypertension Reports, Systolic Hypertension and Cardiovascular Risk Reduction A Clinical Review, P 511-515.

11. Da Silva S., Colósimo C., and Pierin M., (2010): The effect of educational interventions on nursing team knowledge about arterial hypertension, Revista da Escola de Enfermagem da USP, VOL 44, No 2. Available at http://dx.doi.org/10.1590/S008062342010000200035

12. El-arab H., El Salam S., Behalik S., and Eltayeb H., (2012): Nurses, Practice, Knowledge and Attitude towards EvidenceBased Practice at Yanbu general hospital kingdom of Saudi Arabia, Life Science Journal, Vol 9, No 3, P 1062-1071.

13. El-Houfey A., (2007): Knowledge and Practice of Dental Health Care Providers toward Crossinfection Control Measures in Assiut city. Master Thesis, Faculty of Nursing Assiut University.

14. EL-Shazly S., and Mahmoud N., (2007): Measuring the Quality of Life among Elderly with Osteoporosis, ASNJ, Vol 6, No 2, P 23-37.

15. Extremera B., and Gomez P., (2012): Hypertension in the Elderly, International Journal of Hypertension, Volume 2012, Article ID 859176, 4 pages doi:10.1155/2012/859176.

16. Fahmy H., (2010): Quality of life among Visually Impaired Elderly Patients Attending Ophthalmic Clinic at Assiut University Hospital, Geriatric Nursing Department, P35-37.

17. Gamal M., (2005): Establishing standards for prevention of nosocomial infection in the recovery rooms and surgical ward at Elminia university Hospital.

18. Hassan G., (2011): Effect of designed nursing protocol on nurse's knowledge and practice regarding Hemodialysis patients, Assiut University, Faculty of Nursing, Adult Nursing Department, P 52-60.

19. Hassan G., (2011): Effect of designed nursing protocol on nurse's knowledge and practice regarding Hemodialysis patients, Assiut University, Faculty of Nursing, Adult Nursing Department, P 52-60.

20. Hassan K., and Aboulazm F., (2007): Infection control Education, The New Egyptian Journal of Medicine, Vol 36, No 1, P 67-73.

21. Heydari C., Khani S., and Shahhosseini Z., (2012): Health-related quality of life of elderly living in nursing home and homes in a district of Iran: Implications for policy makers, Indian Journal of Science and Technology, Vol 5, No 5, P2782 - 2787.

22. Jesus E., Augusto M., Gusmão J., and Júnior D., Ortega K., and Pierin A., (2008): Profile of hypertensive patients: biosocial characteristics, knowledge, and treatment compliance, Acta Paul Enferm, Vol 21, No 1, P 59-65.

23. Klimm F., Kunz C., and Szecsenyi J., (2010): Health and Quality of Life Outcomes Patientand provider-related determinants of generic and specific health-related quality of life of patients with chronic systolic heart failure in primary care: a cross-sectional study. Available at http://www.hqlo.com/content.

24. Lasheras C., Patterson M., Casado C., and Fernandez S., (2001): Effects of education on the quality of life, diet, and cardiovascular risk factors in an elderly Spanish community population, Expert Aging Res, Vol 27, P257270.

25. Lee W., Kom S., and Leey J., (2005): Health promotion behaviors and quality of life among community-welling elderly in Korea: A crosssectional surve, International journal of Nurse, Vol 43, P 293-300.

26. Lima M., Barros M., César C., Goldbaum M., Carandina L., and Ciconelli R., (2009): Impact of chronic disease on quality of life among the elderly in the state of São Paulo, Brazil: a population-based study, Rev Panam Salud Publica, Public Health, Vol 25, No 4, P 314-21.

27. Luleci E., Hey W., and Subasi F., (2008): Assessing selected quality of life factors of nursing home residents in Turkey. Arch. Gerontology, Vol 46, P 57-66.

28. Mahmoud E., (2007): prevalence of hypertension among people more than 35 years old in Sohag city, Risk factors for hypertension, Sohag University. Faculty of Medicine. Intermedicine Department, P31-33.

29. Melchiors A., Pontarolo R., and Correr C., (2010): Quality of Life in Hypertensive Patients and Concurrent Validity of Minichal-Brazil, Vol 94, No 3, p 337-344.

30. Millman F., (2011): Factors Associated with Nurses Practice Intention to Provide Heart 
Disease Risk and Prevention Education to Women Patients, Dissertations and Theses, Seton Hall University, Available online http://scholarship.shu.edu/dissertations/1238.

31. Mohammed F., (2010): Knowledge, Practice and Attitude of nurses toward universal precautions in outpatient clinics at Assiut University Hospitals, Assiut University, Faculty of Nursing, Community Health Nursing Department, P 109-120.

32. Mostafa M., (2007): Study of hypertensive patient in outpatient clinics in Sohag University Hospital, Faculty of medicine- internal medicine Department, unpublished P 4-67.

33. Naing M., Nanthamongkolchai S., and Munsawaengsub C., (2010): Quality of Life of the Elderly People in Einme Township Irrawaddy Division, Myanmar, Asia Journal of Public Health, Vol 1, No 2, p 4-10.

34. Nutheti R., Shamanna R., Nirmalan K., Keeffe E., Krishnaiah S., Rao N., and Thomas R., (2006): Impact of Impaired Vision and Eye Disease on Quality of Life in Andhra Pradesh, Investigative Ophthalmology and Visual Science Journal, Vol 47, P 4742-4748.

35. Prior J., Jordan K., and Kadam U., (2012): Influence of chronic diseases on long-term change in physical health: a consultation-survey linkage cohort study in general practice, Springer Science Business Media, Quality Life Res (2012), Vol 21, P 581-591.

36. Tajvar M., Arab M., and Montazeri A., (2008): Determinants of health-related quality of life in elderly in Tehran, Iran, BMC Public Health This article is available from: http://www.biomedcentral.com/14712458/8/323.

37. Tweed C., and Tweed M., (2008): Intensive Care Nurses' Knowledge of Pressure Ulcers: Development of an Assessment Tool and Effect of an Educational Program, the American Journal of Critical Care, Vol 17, No 4, P 338344.

38. Viera A., Cohen L., Mitchell M., and Sloane P., (2008): High Blood Pressure Knowledge among Primary Care Patients with Known Hypertension, A North Carolina Family Medicine Research Network (NC-FM-RN) JABFM, Vol 21, No 4, p 300-308.

39. Vloet L., Smits P., Frederiks C., Hoefnagles W., and Jansen R., (2002): Evaluation of skills and knowledge on orthostatic blood pressure measurement in elderly patients, British geriatric society, age and aging, Vol 31, p 211-216.
40. WHO, (2012): world health statistics, Life expectancy, Demography available on the WHO web site (www.who.int).

41. Yang C., Mark W., Rosenbergm B., Wuyi W., Linsheng C., and Hairong L., (2011): Aging, health and place in residential care facilities in Beijing, China. Social Sci. Med, Vol 72, P 365372.

42. Zaky H., (2009): Assessment of Nurses Knowledge and Nursing Intervention for Post stroke Patient Rehabilitation at Elmenia University Hospital and Elmenia General Hospital, Elmenia University, Faculty of Nursing, Adult Nursing Department, P 35-62. 